\title{
Estratégia\&Negócios
}

ISSN 1984-3372

http://www.portaldeperiodicos.unisul.br/index.php/EeN/

\section{A CONTRIBUIÇÃO DO VAREJO PARA O CONSUMO SUSTENTÁVEL: UMA ANÁLISE DAS PRÁTICAS DO WALMART BRASIL JUNTO AOS SEUS STAKEHOLDERS}

\section{THE CONTRIBUTION OF THE RETAIL TO SUSTAINABLE CONSUMPTION: AN ANALYSIS OF WAL- MART BRAZIL PRACTICES AMONG ITS STAKEHOLDERS}

\section{Minelle Enéas da Silva}

Doutorando em Administração pela Universidade Federal do Rio Grande do Sul - UFRGS.

E-mail: minele.adm@gmail.com

Recebido em 23/12/2012. Aprovado em 19/07/2013. Disponibilizado em 30/08/2013. Avaliado pelo Sistema double blind review

R. eletr. estrat. neg., Florianópolis, v.6, n.2, p.66-93, mai./ago. 2013 http://portaldeperiodicos.unisul.br/index.php/EeN/index
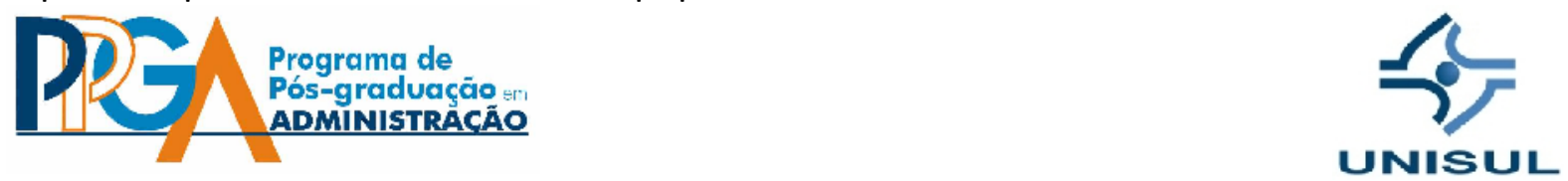

CCopyright 2008 UNISUL-PPGA/Estratégia e Negócios. Todos os direitos reservados. Permitida citação parcial, desde que identificada a fonte. Proibida a reprodução total. Em caso de dúvidas, consulte o editor: ademar.unisul@gmail.com; (48) 3229-1932. 


\section{RESUMO}

Em meio a um conjunto de interações entre diferentes atores no mercado, percebe-se a possibilidade de contribuição empresarial para o surgimento de um novo padrão de consumo, o sustentável. Nesse sentido, assume-se a possibilidade de um novo contexto social, com ações responsáveis e voltadas para essa nova perspectiva. Com isso, o objetivo deste estudo é identificar a contribuição do Walmart Brasil para o consumo sustentável no varejo de supermercados em Recife/PE, sob a ótica de interações sociais apresentadas por Michaelis (2003). Com caráter exploratório e abordagem qualitativa, a pesquisa, conduzida sob a forma de um estudo de caso, considera o consumo sustentável como pano de fundo da pesquisa, na busca pelo reconhecimento das relações entre os atores selecionados, de forma tal que a pesquisa identificou contribuição favorável da empresa em oito dos critérios analisados, com a maioria dos demais em desenvolvimento para uma mudança no setor. Entre os achados, destaca-se a necessidade das organizações do terceiro setor de acrescentar à rede de influências considerada, pois esse ator possui importância e influência nas interações sociais da empresa. Com isso, a contribuição maior do artigo está em apresentar a possibilidade de operacionalização do consumo sustentável.

Palavras-chave: Consumo Sustentável. Stakeholders. Varejo. Supermercados.

\section{INTRODUÇÃO}

Sob o contexto de mudanças ao qual a população mundial vive atualmente, resultante das práticas produtivas e do alto consumo, percebe-se que está havendo uma redução na capacidade de carga do planeta, causada pelos grandes impactos sobre os recursos naturais. Para uma melhor atuação do ser humano no meio, novas perspectivas socioeconômicas, tecnológicas, políticas e ambientais devem estar em consonância com as discussões que vêm sendo desenvolvidas para melhorar a qualidade de vida da sociedade (BUARQUE, 2008). Com isso, com o emergir de um novo modelo de desenvolvimento, o sustentável, entende-se que as características 
individualistas estimuladas pelo capitalismo devem ser direcionadas para uma perspectiva coletiva, com benefícios para toda a sociedade (FOLADORI, 2005).

De acordo com Peattie (2007), para que se consiga incorporar os desafios inerentes a essa forma de desenvolvimento, o principal aspecto a ser visualizado relaciona-se com a ideia de gestão, tendo em vista que os atuais padrões de produção e consumo não são sustentáveis e necessitam de uma melhor orientação. Assim, à medida que um conjunto de atores se torna atuante, tal modelo pode contribuir direta ou indiretamente com essa nova perspectiva (BUARQUE, 2008; CANEPA, 2007; CNUMAD, 1992). Em meio a esse contexto, adéquam-se as discussões inerentes ao consumo sustentável ao se entender que o mesmo, para ser praticado, necessita de um conjunto de inter-relações e de um envolvimento de diferentes stakeholders (JACKSON, 2007; MICHAELIS, 2003; PNUMA, 2001).

Assim sendo, percebe-se que diferentes stakeholders devem atuar em uma rede de influências, na qual cada um pode assumir papéis e responsabilidades para facilitar a efetivação desse padrão emergente de consumo, dentre os quais se observam os governos, as empresas e os demais atores da sociedade (mídia, indivíduos etc.) (MICHAELIS, 2003). Na literatura acadêmica sobre Consumo Sustentável (CS), as discussões ainda se apresentam como incipientes, todavia, percebe-se a possibilidade de atuação em destaque por parte das empresas ao incorporar novos comportamentos às suas atividades (JACKSON; MICHAELIS, 2003; JACKSON, 2007). Com isso, optou-se por focar o estudo em como as ações empresariais responsáveis podem estimular o Consumo Sustentável.

Sob esse campo de argumentação, nota-se que atualmente a maioria das empresas ainda tem dificuldade em entender seu papel de facilitadora à prática sustentável do consumo (MICHAELIS, 2003). Assim sendo, parte-se da premissa que, com a incorporação de práticas responsáveis, as empresas em meio às interações sociais que estão inseridas podem auxiliar para o CS. Ao observar a dinâmica empresarial vivenciada, percebe-se que muitas são aquelas empresas que estão reestruturando suas atividades e que apresentam uma preocupação com as questões voltadas para o desenvolvimento sustentável, entre elas, destaca-se o Walmart (GUNTHER, 2006; SILVA; SANTOS, 2011). Atuante no Brasil desde 1995, essa empresa R. eletr. estrat. neg., Florianópolis, v.6, n.2, p.66-93, mai./ago. 2013 
supermercadista trabalha com a proposta de ser uma loja de conveniência a partir das características da comunidade local (WALMART BRASIL, 2010).

Diante de todas essas considerações, o objetivo do presente estudo é identificar qual a contribuição do Walmart Brasil para a efetivação do consumo sustentável no varejo de supermercados em Recife/PE, sob a ótica de interações sociais apresentadas por Michaelis (2003). Para tanto, assume-se o Hipermercado Bompreço como a marca nordestina a ser estudada. Como forma de melhor compreender o objetivo proposto, o artigo está dividido em quatro partes além da introdução. Em seguida, serão observados os aspectos teóricos norteadores da pesquisa. Em outro momento, os procedimentos metodológicos, a apresentação e a análise dos resultados. E, por fim, as considerações finais. Assim, torna-se facilitada a apresentação da contribuição teórico-empírica da pesquisa para as discussões acadêmicas.

\section{DISCUSSÃO TEÓRICA}

\subsection{DESENVOLVIMENTO SUSTENTÁVEL}

Ao longo dos últimos anos, o desenvolvimento sustentável vem sendo debatido como uma visão alternativa a um conjunto de transformações que ocorrem em todo o contexto mundial. Sua discussão permeia, segundo Kte'pi (2009), a ideia de uma preocupação a longo prazo capaz de manter atividades e disponibilidades de recursos, com o intuito de melhor trabalhar os aspectos ambientais, econômicos e sociais. Nesse sentido, torna-se mais clara a necessidade de mudança do atual modelo de desenvolvimento utilizado ao se considerar que a ideia básica para o alcance do Desenvolvimento Sustentável (DS) está relacionada com a harmonização de suas dimensões no sentido de atender às necessidades das gerações atuais sem comprometer a satisfação das necessidades das futuras gerações (ELKINGTON, 2001; SACHS, 2007; WCDE, 1987).

Nesse sentido, o conceito mais difundido para desenvolvimento sustentável foi definido no Relatório de Brundtland, no qual ele é entendido como "um R. eletr. estrat. neg., Florianópolis, v.6, n.2, p.66-93, mai./ago. 2013 
processo de mudança em que a exploração dos recursos, a direção dos investimentos, a orientação do desenvolvimento tecnológico e a mudança institucional estão todos em harmonia", a fim de que as necessidades humanas possam ser satisfeitas atualmente e no futuro (WCDE, 1987, n.p.). Para tanto, entende-se como necessária a busca pela harmonização entre as dimensões básicas do desenvolvimento sustentável, quais sejam: a econômica, a social e a ambiental (SACHS, 2007; VAN BELLEN, 2005), de modo que seja possível a prática de diferentes papéis sociais por vários atores na sociedade.

Com isso, percebe-se a necessidade de que todos os stakeholders alterem suas práticas adotadas para que haja compreensão, incorporação e atitudes com resultados mais positivos para tais transformações. Assim, para que o desenvolvimento sustentável possa ser efetivado, é necessária uma interação entre esses atores, realizada com práticas mútuas de pressão e com uma complementaridade nas atividades desenvolvidas por cada um. Esse fato é corroborado por Martins e Cândido (2008) quando reconhecem que os sistemas de atores são interligados e que entre si exercem influências mútuas, o que indica que para que o DS possa ser efetivado, o envolvimento entre os mesmos deve ser considerado. Ao focar no estudo das empresas, Peattie (2007) indica que as mesmas fazem parte de um amplo sistema econômico e social e precisam se orientar para a criação de oportunidades e progressos nesse sentido.

Com o mesmo raciocínio, Elkington (2001) indica ser papel das empresas, o atendimento das três dimensões básicas da sustentabilidade, o chamado Triple Bottom Line, repassando práticas responsáveis para todos os participantes de sua cadeia de valor, havendo, assim, uma participação mais ativa em uma dinâmica de mercado. Com essa perspectiva de mudanças nas práticas desenvolvidas, há a possibilidade de reestruturação tanto nas formas de produção como no padrão de consumo de toda a população (TUKKER et al., 2008). Portanto, uma nova visão desenvolvimentista, segundo Schumacher (2001), deve estar alinhada à redução tanto da produção de bens que geram grande impacto ambiental como nas taxas de consumo da sociedade, indicando uma reestruturação nas práticas empresariais. 
Corroborando a ideia, Foladori (2005, p. 17) indica que "para se limitar o consumo, é também necessária uma mudança nos processos de produção para obter produtos mais duradouros e tecnologias mais eficientes e limpas no uso dos recursos". Apesar dessas considerações, assumindo que as empresas estão inseridas em um contexto de interações sociais que surge de um envolvimento coletivo de diferentes atores (MICHAELIS, 2003), torna-se necessário discutir junto a esses atores aspectos referentes a uma prática mais responsável de produção e, por consequência, de consumo. Desse modo, podem-se iniciar as discussões sobre a perspectiva do consumo sustentável.

\subsection{CONSUMO SUSTENTÁVEL}

Considerando o contexto de mudanças, entende-se que há, atualmente, a necessidade de revisão nas formas de produção e consumo praticadas, tendo em vista a efetivação do chamado consumismo que vem sendo observado na maioria das populações ao redor do mundo, como parte da cultura de muitos países em meio à chamada sociedade de consumo (ASSADOURIAN, 2010). Assim, verifica-se como necessária a mudança no paradigma de consumo, de modo que seja possível a continuidade de consumo em escala mundial. Ao iniciar o direcionamento das ações humanas para uma perspectiva relacionada com o desenvolvimento sustentável, torna-se possível incluir a discussão do consumo com uma apreciação mais coletiva e preocupada com a continuidade da sociedade no planeta.

No contexto social, a mudança nas práticas de consumo "reflete o momento cultural ao qual a mesma está inserida, perante as dinâmicas e demandas requeridas, necessitando, assim, de um direcionamento coletivo para a efetivação de um desenvolvimento emergente, o sustentável" (SILVA, 2011, p. 29). Com isso, entende-se que, seguindo a ideia de mudança de paradigma e considerando-a viável, estão surgindo novas preocupações do consumidor, as quais mudam o foco individualista de seu consumo para uma visão mais ampla em termos de consciência do mesmo (MICHAELIS, 2000). Surge, portanto, na visão desses autores, o movimento na sociedade por um consumo mais responsável. 
Para se trabalhar com o padrão sustentável de consumo, não se devem observar apenas as ações desenvolvidas pelos consumidores, mas, sim, um conjunto de interações sociais que são desenvolvidas de modo tal que se consiga trabalhar a perspectiva política desenvolvida em meio às relações de consumo em determinado setor econômico. Assim, percebe-se que, segundo Jackson (2004; 2007), para que o Consumo Sustentável (CS) possa ser praticado, é necessária uma adequação dos padrões de consumo à nova realidade social, entendendo que a partir da redução no consumo de boa parte dos materiais, bem como de um redirecionamento das práticas desenvolvidas, seu alcance se torna facilitado.

De acordo com Portilho (2005), o CS surge como uma nova perspectiva em relação às estratégias públicas no que diz respeito à esfera do consumo, às novas formas de produção das empresas, bem como às mudanças comportamentais dos indivíduos no mercado. O mesmo pode ser alcançado pelo compartilhamento de responsabilidades, em meio a uma nova atuação em todas as esferas - econômicas, sociais e políticas, representadas genericamente pelo governo, pelas empresas e pelos demais atores da sociedade, enfim, por cada indivíduo-cidadão que possua a autonomia e o entendimento nessa prática (CORTEZ; ORTIGOZA, 2007; MICHAELIS, 2000; 2003). De forma direta, Jackson (2004) indica que a prática sustentável do consumo envolve não apenas consumir o mesmo, mas diferente e eficientemente.

Assim sendo, entende-se que para que seja posto em prática o consumo sustentável, é necessário levar-se em consideração as relações de influência que esses stakeholders possuem sobre o consumo, no qual cada um deve assumir a identidade de seus papéis individuais dentro da ideia de coletividade que é utilizada para o estudo da temática. Entendendo que esse é um processo cultural, complexo e capaz de auxiliar a efetivação de um novo paradigma de consumo em relação à perspectiva emergente de desenvolvimento, percebe-se que os diferentes autores que discutem consumo sustentável direcionam seus posicionamentos para o papel dos stakeholders envolvidos nesse processo. Desse modo, torna-se relevante entender os compromissos e a responsabilidade que os mesmos possuem nesse sentido.

Assim, frente ao consumo sustentável, cada ator necessita assumir responsabilidades distintas, mas convergentes com o objetivo maior que envolve a R. eletr. estrat. neg., Florianópolis, v.6, n.2, p.66-93, mai./ago. 2013 
reestruturação no paradigma de consumo utilizado. Nessa perspectiva, além das empresas que estão inseridas em diferentes estruturas e que possuem diferentes comportamentos no mercado, outros atores podem ser visualizados nesse sistema, direcionando-se para o consumo sustentável, os quais foram identificados: os fornecedores, os competidores, as instituições financiadoras, as universidades, a mídia, o governo e os indivíduos (dentro do contexto da comunidade) (MICHAELIS, 2000; 2003; MONT; PLEPYS, 2007). Para que seja possível reconhecer os papéis desenvolvidos, faz-se necessário realizar uma caracterização dos mesmos.

Levando em consideração os governos dentro da perspectiva do consumo sustentável, esses podem assumir o papel de apoiar pesquisas para o fornecimento de informações de produção e consumo, tanto para a indústria como para os consumidores (PNUMA, 2001). Assim, entre outras ações, os governos têm o papel de estimular e incentivar outros atores por meio de políticas públicas, programas educacionais, fomento e financiamento de projetos (PNUMA, 2001; SILVA; GÓMEZ, 2011), facilitando a efetivação de mudanças em diferentes áreas da sociedade. A partir dessas considerações, percebe-se a possibilidade de uma atuação ativa e intensa do governo nas relações sociais; com isso, os demais atores também podem se tornar ativos nesse processo. Por fim, observando a responsabilidade do indivíduo, o mesmo assume um papel importante no processo de definição da prática de consumo sustentável.

Nesse sentido, esse aspecto de mudança no pensamento individual com um comportamento de consumo consciente, segundo o PNUMA (2001), apresenta-se como um desafio aos indivíduos, tendo em vista que estes recebem influências e pressões contra essa nova atitude e, na maioria das vezes, assumem a opção de não fazê-lo. Tal fato é discutido por Mont e Plepys (2007) como um aspecto de limitação na forma de atuação e no processo de escolhas individuais. Com isso, ao se focar em uma perspectiva mais cidadã, os indivíduos podem utilizar seu poder de decisão, por exemplo, durante as eleições para escolher melhor seus governantes. Além dos indivíduos, são muitos os atores que compõem a sociedade e devem atuar, todavia, para o presente estudo, foca-se na discussão sobre o papel das empresas para uma melhor compreensão sobre a temática. 
2.2.1 O papel das empresas para o consumo sustentável

Na busca pela identificação da contribuição que as empresas possuem para o consumo sustentável, optou-se por estudar o modelo teórico apresentado por Michaelis (2003), o qual indica que para atuar no mercado de forma responsável, as empresas devem estar envolvidas em uma rede de influências que se caracterizam principalmente pelo processo de interações sociais. Para que essa argumentação possa ser considerada, Steiner e Steiner (2006) indicam existir como stakeholders na sociedade: os acionistas, os clientes, os funcionários, a comunidade, o governo, a mídia, os competidores, os fornecedores, as associações comerciais, os grupos de interesse político, os sindicatos, os partidos políticos, a biosfera terrestre, as futuras gerações, os pobres, as instituições de ensino, entre outros.

A partir da identificação desses atores, torna-se questionável a utilização apenas dos atores apresentados por Michaelis (2003) em sua rede de influências, tendo em vista que o mesmo não contempla de forma abrangente a quantidade de interações possíveis de serem utilizadas, podendo haver a atuação de outros, que, por alguma questão, não foram inseridos no mapeamento do autor. Todavia, salienta-se que a rede de influências, diferentemente do modelo de stakeholders de Steiner e Steiner (2006), visa aos aspectos relacionados ao CS. Portanto, deve-se observar até que ponto as relações propostas podem estar envolvidas em um único processo, bem como verificar a aplicabilidade e efetividade da atuação de cada ator destacado para a promoção de um consumo sustentável.

É condição sine qua non para a efetivação do Consumo Sustentável a existência desse conjunto de interações. Todavia, deve-se considerar uma nova maneira de visualizar aspectos e fatos até então não identificados ou utilizados por parte de cada ator, ou seja, deve-se assumir uma perspectiva de pensamento diferenciada da atual. Nesse sentido, com o foco nas organizações, é necessário entender como essas atuam para que esse padrão de CS possa ser praticado. Desse modo, Michaelis (2003) sugere a necessidade de incorporação às atividades organizacionais de novas formas de atuação, tudo por meio de um processo de 
mudanças nas ações da empresa para que se consiga auxiliar essa nova perspectiva de consumo.

Em geral, a comunidade empresarial tem interpretado o CS como apenas o consumo de produtos sustentáveis ou ecologicamente corretos. No entanto, o que se percebe é que existe uma complexidade maior, por isso se discute a ideia de interações sociais (MICHAELIS, 2003). Nesse contexto, três dimensões devem ser observadas: (1) o desenvolvimento de novas tecnologias e práticas, (2) as mudanças nos incentivos econômicos e (3) a mudança cultural, que, ao ser incorporada pelas empresas, pode contribuir para o Consumo Sustentável. Corroborando com isso, Málovics, Csigéné e Kraus (2008) afirmam a possibilidade de atuação das empresas na direção de um consumo mais ou menos sustentável, devendo-se observar os comportamentos adotados pelas mesmas.

A partir das considerações até então apresentadas, na medida em que essas dimensões estão sendo observadas e praticadas pelas empresas, estas se interrelacionam e se complementam de maneira tal que muitas vezes as características inerentes a uma dimensão específica do modelo podem ser observadas em práticas desenvolvidas em outra das possíveis dimensões. Assim, para cada dimensão, a compreensão de seus aspectos facilita o entendimento do modelo de Michaelis (2003) e pode ser observada a partir da articulação de categorias de análise, já que, de acordo com o estudo do autor, as mesmas não foram apresentadas de forma direta, mas podem ser visualizadas nos conteúdos teóricos que envolvem a temática. Vale salientar, ainda, que como são poucos os estudos sobre CS. Portanto, esse fato apresenta-se como um limite de pesquisa. 
Quadro 1 - Categorias teóricas e critérios de análise para a identificação da contribuição responsável das empresas para o consumo sustentável

\begin{tabular}{|c|c|c|c|}
\hline Dimensão & Categoria teórica & Definição da categoria & Critérios de análise \\
\hline \multirow{8}{*}{ 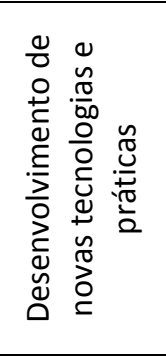 } & \multirow{4}{*}{ Ecoeficiência } & \multirow{4}{*}{$\begin{array}{l}\text { Refere-se à prática empresarial que busca } \\
\text { conciliar o crescimento econômico e a } \\
\text { mitigação dos impactos ambientais. }\end{array}$} & Reciclagem \\
\hline & & & Reutilização \\
\hline & & & Estrutura física da loja \\
\hline & & & Certificação \\
\hline & \multirow{4}{*}{$\begin{array}{l}\text { Práticas de } \\
\text { consumo próprias }\end{array}$} & \multirow{4}{*}{$\begin{array}{l}\text { Refere-se às práticas empresariais voltadas à } \\
\text { preocupação com consumo de energia e água e } \\
\text { à gestão de resíduo e gestão de transportes. }\end{array}$} & Água \\
\hline & & & Energia \\
\hline & & & Gestão de resíduos \\
\hline & & & Transportes \\
\hline \multirow{6}{*}{ 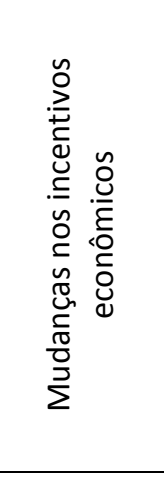 } & \multirow{2}{*}{$\begin{array}{l}\text { Incentivos do } \\
\text { governo }\end{array}$} & \multirow{2}{*}{$\begin{array}{l}\text { Relaciona-se às respostas que as empresas dão } \\
\text { aos incentivos ou regulamentações realizadas } \\
\text { pelo governo. }\end{array}$} & Comportamento reativo \\
\hline & & & Negociação \\
\hline & \multirow{2}{*}{$\begin{array}{l}\text { Elos da cadeia de } \\
\text { suprimentos }\end{array}$} & \multirow{2}{*}{$\begin{array}{l}\text { Envolve a disseminação de práticas } \\
\text { sustentáveis em todos os elos da cadeia de } \\
\text { suprimentos, de modo que as ações de cada } \\
\text { intermediário se tornem responsáveis. }\end{array}$} & $\begin{array}{l}\text { Disseminação de práticas } \\
\text { responsáveis }\end{array}$ \\
\hline & & & Capacidade de influência \\
\hline & \multirow{2}{*}{ Edição de escolha } & \multirow{2}{*}{$\begin{array}{l}\text { Refere-se às decisões que controlam } \\
\text { diretamente os impactos de consumo }\end{array}$} & $\begin{array}{l}\text { Processo decisório } \\
\text { responsável }\end{array}$ \\
\hline & & & $\begin{array}{l}\text { Análise da procedência } \\
\text { do produto a ser vendido }\end{array}$ \\
\hline \multirow{7}{*}{ 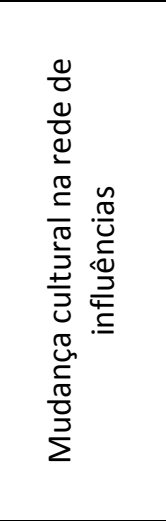 } & \multirow[b]{2}{*}{$\begin{array}{l}\text { Cidadania } \\
\text { corporativa }\end{array}$} & \multirow[b]{2}{*}{$\begin{array}{l}\text { Refere-se ao aspecto facilitador e à } \\
\text { incorporação de práticas responsáveis por } \\
\text { parte dos colaboradores. }\end{array}$} & Boa cidadania corporativa \\
\hline & & & $\begin{array}{l}\text { Disseminação do } \\
\text { consumo consciente } \\
\text { junto aos funcionários }\end{array}$ \\
\hline & \multirow{2}{*}{$\begin{array}{l}\text { Marketing } \\
\text { responsável }\end{array}$} & \multirow{2}{*}{$\begin{array}{l}\text { Envolve o processo comunicacional que busca } \\
\text { divulgar um pensamento mais consciente junto } \\
\text { aos seus consumidores. }\end{array}$} & $\begin{array}{l}\text { Composto de marketing } \\
\text { responsável }\end{array}$ \\
\hline & & & Relatório social \\
\hline & \multirow{3}{*}{$\begin{array}{l}\text { Diálogo com } \\
\text { stakeholders }\end{array}$} & \multirow{3}{*}{$\begin{array}{l}\text { Refere-se ao processo de interação da empresa } \\
\text { com stakeholders em seu processo de tomada } \\
\text { de decisão. }\end{array}$} & Relação com a mídia \\
\hline & & & $\begin{array}{l}\text { Relação com a } \\
\text { comunidade }\end{array}$ \\
\hline & & & $\begin{array}{l}\text { Relação com instituições } \\
\text { não governamentais }\end{array}$ \\
\hline
\end{tabular}

Fonte: Adaptado de Silva (2011).

A partir de todas as considerações realizadas, entende-se que existe uma noção integradora entre o consumo sustentável e o desenvolvimento sustentável e que os diferentes stakeholders que atuam em um determinado setor econômico, dentre os quais as empresas, necessitam estar desenvolvendo suas responsabilidades de maneira tal que a mudança que se apresenta almejada possa de fato ser posta em prática. Assim sendo, considerando a empresa como o foco central da pesquisa, bem como compreendendo quais são os principais direcionamentos de análise, torna-se necessário compreender quais foram os procedimentos metodológicos que guiaram 
sua realização, de modo que os passos e as características de pesquisa possam ser mais bem considerados.

\section{PROCEDIMENTOS METODOLÓGICOS}

Com o objetivo de identificar qual a contribuição do Walmart Brasil para a efetivação do consumo sustentável no varejo de supermercados em Recife/PE, sob a ótica de interações sociais apresentadas por Michaelis (2003), o desenvolvimento da pesquisa efetivou-se por meio de uma abordagem qualitativa, na medida em que se busca entender a efetivação de uma dada relação (OLIVEIRA, 2005). Para tanto, foram realizadas duas etapas, uma inicial exploratória, para o reconhecimento do contexto argumentativo-teórico e das características pertinentes ao setor e a empresa, e uma segunda, com a descrição de como foi observado o fenômeno no decorrer da pesquisa (COOPER; SHINDLER, 2003; CRESWELL, 2010).

Ao utilizar a argumentação de que as empresas podem contribuir para o consumo sustentável em determinado setor econômico, toma-se como estratégia de pesquisa o estudo de caso. Sua escolha é justificada neste estudo, tendo em vista a visualização macro do contexto ao qual a empresa selecionada está inserida, bem como as características singulares da mesma, o que facilita o atendimento do objetivo (GOLDENBERG, 2009). Para tanto, selecionou-se a marca Hipermercado Bompreço, integrante do Walmart Brasil, considerando sua relevância econômica para a Região Nordeste. São tidos como métodos de verificação, então, o levantamento bibliográfico e documental, a aplicação de questionários, bem como a realização de entrevistas semiestruturadas e de observação direta não participante (FLICK, 2004; MARCONI; LAKATOS, 2010).

Participaram do processo de coleta de dados como representantes do Walmart Brasil: o Diretor Nacional de Comunicação, a Gerente Regional (NE) de Comunicação e a Coordenadora do Instituto Walmart, que respondem diretamente sobre todas as práticas da empresa voltadas para a questão da sustentabilidade. Além disso, para uma das categorias aplicou-se questionários com 51 colaboradores, a partir de uma amostra não probabilística por acessibilidade. As observações foram realizadas R. eletr. estrat. neg., Florianópolis, v.6, n.2, p.66-93, mai./ago. 2013 
nos bairros da Iputinga, Casa Forte, Boa Viagem, Ipsep, além do Hiper Bompreço localizado no Shopping Recife. Não houve critério de seleção, já que a intenção foi a observação de todas as lojas, no entanto, com a saturação das práticas identificadas nas lojas visitadas, não foram realizadas observações em todas as lojas.

Definiu-se como procedimento de análise dos dados a análise de conteúdo na perspectiva de Bardin (2009) para as entrevistas realizadas, as informações contidas no website e nos documentos utilizados, bem como na análise da observação, que foi realizada tanto no momento das entrevistas como nas diferentes lojas visitadas. Para a análise das categorias, foram utilizados os parâmetros de análises definidos por Silva (2011) para facilitar a aplicabilidade e operacionalização da pesquisa. Com as respostas dos métodos de verificações, tornou-se possível a realização de uma triangulação de dados para efetivar a validação dos resultados encontrados (CRESWELL, 2010).

\section{APRESENTAÇÃO E DISCUSSÃO DOS RESULTADOS}

\subsection{WALMART BRASIL E SUAS PRÁTICAS SOCIOAMBIENTAIS}

Os negócios do Walmart começaram a ser realizados no Estado do Arkansas (EUA) em 1962 e atualmente estão sendo praticados em 15 diferentes países sob o foco de multimarcas. No Brasil, suas atividades começaram a ser desenvolvidas no interior de São Paulo em 1995, e com um processo de expansão, a empresa entrou no mercado nordestino em 2004, a partir da aquisição da rede Bompreço de supermercados. Apesar de conhecida em contexto global, a empresa possui um destaque e uma imagem no mercado por muitos questionada - a de uma empresa socioambientalmente responsável.

Segundo o Diretor Nacional de Comunicação do Walmart, responsável pela área de sustentabilidade da empresa, a preocupação com o problema do aquecimento global e a busca pelo atendimento da missão empresarial, que é vender por menos para as pessoas viverem melhor (WALMART BRASIL, 2010), foram estímulos para o início das práticas responsáveis ao entender que para uma melhor qualidade de vida dos seus consumidores, a empresa deve direcionar suas atividades para um R. eletr. estrat. neg., Florianópolis, v.6, n.2, p.66-93, mai./ago. 2013 
desenvolvimento sustentável. De maneira institucionalizada, o Walmart começou a assumir, segundo o diretor entrevistado, como pilares estratégicos corporativos, Crescimento, Rentabilidade e Responsabilidade Socioambiental Empresarial - na perspectiva da sustentabilidade.

Esse novo comportamento organizacional só começou a ser desenvolvido a partir do momento em que um conjunto de interações começou a ser realizado no mercado. No processo de definição de quais seriam as responsabilidades assumidas pela empresa, houve uma interação política tanto por meio de reuniões com representantes do governo como com outros atores, como, por exemplo, os funcionários de grande parte das lojas, a organização não governamental chamada de Conservação Internacional, além da consultoria que facilitou a identificação do impacto da empresa no ambiente (Gunther, 2006), o que demonstra uma articulação efetiva para que o discurso da empresa pudesse ser praticado.

4.2 A CONTRIBUIÇÃO RESPONSÁVEL DO WALMART BRASIL PARA O CONSUMO SUSTENTÁVEL NO VAREJO DE SUPERMERCADOS JUNTO AOS STAKEHOLDERS ATUANTES

À medida que diferentes interações sociais se tornaram necessárias, conseguiu-se identificar com a pesquisa que os dez stakeholders mais relevantes para o atendimento das necessidades sociais e ambientais do Walmart Brasil são funcionários, clientes, fornecedores, governo municipal, estadual e federal, mídia, organizações não governamentais, comunidade, e sindicatos e associações de classe, respectivamente. Segundo o atual presidente, Marcos Samaha, o engajamento dos atores na rede de stakeholders da empresa envolve "a busca por mudanças nos padrões de consumo e produção e uso de recursos naturais" (WALMART BRASIL, 2011, p. 10), pela construção de um futuro mais justo (SILVA; SANTOS, 2011).

As discussões até então realizadas envolveram a compreensão ampla de quais os stakeholders interagem com o Walmart Brasil. Mas a partir desse momento, salienta-se que o foco está nas práticas desenvolvidas pela marca Hiper Bompreço, no qual, mesmo que as considerações saiam de uma discussão genérica, busca-se R. eletr. estrat. neg., Florianópolis, v.6, n.2, p.66-93, mai./ago. 2013 
visualizar as ações desenvolvidas em Recife/PE. No que se refere à dimensão do desenvolvimento de novas práticas e tecnologias, de acordo com as informações levantadas ao longo da pesquisa sobre ecoeficiência, identificou-se que não há um processo de reutilização de materiais bem articulado, assim como uma certificação que seja acreditada interna ou externamente à empresa. Para a gerente entrevistada, o que existe é o Selo Clube do Produtor, utilizado de forma meramente ilustrativa para indicar que o produto possui classificação de orgânico.

Para que esse estímulo à prática de reciclagem do consumidor ocorra, um conjunto de parcerias é realizado no sentido de melhorar o escoamento e entrega dos materiais, com a busca pela redução máxima de impacto sobre o meio ambiente. Identificam-se parcerias com as empresas Coca-cola, OnduNorte e Motorola, bem como com instituições não governamentais, como a cooperativa Pró-Recife (WALMART BRASIL, 2011). Essa prática é internalizada pelos funcionários, já que, durante o processo de observação na loja Casa Forte, o pesquisador, ao interagir com alguns deles, questionou-os sobre o destino final do material, no que indicaram a efetivação do processo de reciclagem, que envolve a separação, a prensa, a criação de fardos e a entrega para os destinos mais corretos.

Apesar dessas considerações, em Recife nenhuma das lojas do Hiper Bompreço apresenta qualquer desses critérios de loja ecoeficiente, tendo em vista que são lojas preexistentes resultante do processo de aquisição sobre a marca Bompreço no Nordeste. Esse fato foi justificado pelos entrevistados quando os mesmos indicaram que práticas de ecoeficiência nas lojas são principalmente utilizadas na construção de novas lojas, isso prejudica a região, já que não há previsão alguma de uma nova loja ser construída na localidade. Mesmo assim, existe alternativa, posto que, segundo o ex-presidente Hector Núñez, nos locais onde novas lojas não são previstas, a inserção de aspectos de ecoeficiência será realizada durante as reformas realizadas, a fim de reduzir o impacto ambiental (WALMART BRASIL, 2009).

Quando se discutiu as práticas próprias de consumo, buscou-se identificar os aspectos relacionados com a gestão da água, da energia e dos resíduos sólidos na empresa. Com a análise dos relatórios de sustentabilidade, percebe-se que há um planejamento sobre esses aspectos, todavia, no Hiper Bompreço esses planos R. eletr. estrat. neg., Florianópolis, v.6, n.2, p.66-93, mai./ago. 2013 
não são identificados em sua completude, tendo em vista a falta de lojas ecoeficientes na cidade e a inexistência de qualquer planejamento de reformas nas lojas já existentes. Segundo a gerente entrevistada, os planos vão gradativamente sendo colocados em prática na busca pela redução do desperdício e por melhores condições para o meio ambiente. Já quanto à variável gestão de transportes, a preocupação com essa prática de consumo levou o Walmart Brasil a observar seu impacto ambiental relacionado, por exemplo, com a emissão de gases de efeito estufa.

Essas considerações estão alinhadas às considerações apresentadas por Buenstorf e Cordes (2008) e Muster (2011), que indicam a possibilidade de incorporação e prática por parte dos colaboradores, por meio de um processo de aprendizagem e mudança nos aspectos culturais da empresa. Tal fato está alinhado com os aspectos que serão discutidos no tópico referente à cidadania corporativa, que busca perceber a relação existente nesse processo. As considerações até então realizadas indicam aspectos internos à empresa, o que indica interações sendo realizadas com fornecedores, funcionários, clientes e comunidade local.

Após essa visão, identificando os aspectos relacionados à mudança nos incentivos econômicos, que, segundo Michaelis (2003), não se refere apenas às influências do governo, mas também às interações no setor econômico, percebeu-se um direcionamento da empresa para um comportamento ativo no setor, já que essa "foi a primeira empresa de varejo a apoiar a campanha 'Saco é um Saco', realizada pelo Ministério do Meio Ambiente com o objetivo de conscientizar as pessoas de que a sacola pode ser útil, mas nem sempre é necessária, e de que existem formas de otimizar o uso" (WALMART BRASIL, 2009, p. 37). Para a gerente entrevistada, "o Governo é parceiro e incentiva o varejo, sim, quando nos coloca em discussões como essa, por exemplo, da sacola plástica".

Segundo a empresa, pela construção de um novo varejo, o Walmart Brasil contribui com o debate e a adoção de medidas para o fortalecimento no setor (WALMART BRASIL, 2011). Esses debates de negociações envolvem a conversação direta com o governo, ou ainda, a interação da empresa com associações representantes do governo na busca pela construção de novas relações no mercado. Um dos exemplos de negociação que pode ser destacado refere-se às discussões a R. eletr. estrat. neg., Florianópolis, v.6, n.2, p.66-93, mai./ago. 2013 
respeito de leis, normas e iniciativas aplicáveis ao varejo, como a Política Nacional de Gestão de Resíduos Sólidos (PNRS). Essa interação é complementada pelo Diretor Nacional de Comunicação da empresa, quando o mesmo afirma que:

\begin{abstract}
A gente [Walmart] tem parceria para fazer pesquisas junto com o Ministério do Meio Ambiente, pra entender o que é que o brasileiro pensa de sustentabilidade... A gente tem desde aquelas campanhas de marketing, também com os Ministérios... A gente tem desde um trabalho de aproximação com a associação de supermercados e com o Congresso Nacional, na questão da lei dos resíduos sólidos.
\end{abstract}

Como foi observado no mapeamento dos stakeholders apresentado no início das análises, continuamente o Walmart Brasil interage com o governo, seja no contexto nacional, estadual ou municipal. No que se refere aos fornecedores, segundo a empresa, "a mesma adota um modelo de estímulo mútuo e crescimento integrado, visando a consolidar uma rede de negócios sustentáveis dos pontos de vista econômico, social e ambiental" (WALMART BRASIL, 2009, p. 53). Isso é visualizado nas suas relações comerciais, já que a empresa possui uma política de ética na cadeia de suprimentos que é aplicada a todos os fornecedores.

Esse aspecto pode ser visualizado a partir do programa "Clube de Produtores", que visa a integrar pequenos fornecedores, no caso de produtos agrícolas, à perspectiva responsável da empresa, já que, para eles, os incentivos são dados para que seus produtos estejam apresentados no salão de vendas. Com isso, os mesmos deveriam possuir um local de destaque, o que ocorre claramente na Região Sudeste pela observação do pesquisador, só que, de acordo com as observações no Recife, identificou-se a inexistência de um destaque amplo desses produtos, algo que ocorreu apenas na loja Hiper Bompreço de Boa Viagem.

Apesar dessas considerações, ao entender que interações são necessárias, com cada ator desenvolvendo seu papel de maneira responsável e alinhado com o paradigma emergente de desenvolvimento (JACKSON, 2004; 2007; MICHAELIS, 2000; 2003), o Walmart Brasil indica buscar continuamente desempenhar um papel ativo para assegurar a responsabilidade em toda a cadeia de valor (WALMART BRASIL, 2009). Isso sugere uma mudança em seu comportamento na medida em que seus 
valores, sua cultura e suas ações começam a ser desenvolvidas sob uma nova perspectiva (SILVA; SANTOS, 2011).

No que tange à variável processo decisório responsável, entende-se que todas as decisões que são tomadas interferem na dinâmica da empresa. No entanto, quando as mesmas apresentam-se responsáveis ou voltadas para uma perspectiva social e ambiental, a contribuição empresarial apresenta-se como positiva (TUKKER et al., 2008; WBCSD, 2008). Já no que se refere à análise da procedência do produto a ser vendido, a edição de escolha da empresa impacta diretamente nos produtos oferecidos em loja e facilita o estímulo ao consumo consciente, por exemplo (WBCSD, 2008). Percebe-se que essa variável está relacionada ao Pacto pela Sustentabilidade Walmart Brasil, o qual indica, entre outras ações, a preocupação com a procedência dos produtos.

Como se pode observar em todas as discussões realizadas até então, muitas interações devem ser realizadas para que os incentivos econômicos possam ser modificados no âmbito do Consumo Sustentável. Realizando uma análise da última dimensão sobre o modelo de Michaelis (2003), pode-se perceber que essa é a que mais contribui para o CS, de acordo com as práticas da empresa, pois envolve a mudança cultural em sua rede de influências. Ao realizar a aplicação dos questionários junto aos colaboradores, percebe-se que ao se basear no modelo de Carroll (1998), as médias totais das dimensões se apresentam acima de 4,0, com uma média geral de 4,18, o que indica um direcionamento para uma cidadania corporativa.

Identificou-se que uma série de ações são desenvolvidas para tornar claro aos funcionários o conceito de sustentabilidade e disseminar formas de aplicá-lo na prática, dentro e fora de seu ambiente, o que contribui para as disseminação das práticas empresariais. No que tange ao composto de marketing responsável, no Walmart Brasil, percebem-se estratégias relacionadas aos formatos de loja, merchandising e precificação (WALMART BRASIL, 2011). Foram identificados os quatro elementos, mas de forma suave, ao longo do ano e com maior destaque dentro do chamado Mês da Terra, de acordo com o depoimento da gerente entrevistada, "a gente incorporou a sustentabilidade como uma sazonalidade pra deixar ainda mais 
forte com o Mês da Terra... A gente tem alguns materiais de sinalização visual sobre sustentabilidade o ano inteiro, mas muito suave, porque tem a campanha máster".

Assim sendo, a partir dos aspectos supracitados, percebe-se que no Walmart Brasil há um direcionamento para a prática de um composto de marketing responsável. Todavia, deve-se compreender que no Hiper Bompreço do Recife essa iniciativa não se apresenta como efetiva por completo, já que durante a observação do pesquisador poucas dessas iniciativas foram identificadas, e, mesmo durante o período do Mês da Terra, não houve uma efetiva realização da campanha promocional por falha na construção do material. Quanto aos relatórios sociais, esses servem para ampliar o conhecimento e reconhecimento da empresa do ponto de vista de seus consumidores e de todos os outros atores que estejam atuando no setor de supermercados, já que servem para apresentar as ações que estão sendo desenvolvidas.

No que se refere à variável diálogo, com os stakeholders, pode-se verificar uma efetiva relação da empresa com os três stakeholders considerados nesse momento (Ver Quadro 01), o que favorece sua contribuição ao consumo sustentável no setor. O maior destaque se dá na relação com a comunidade na qual o programa de desenvolvimento local integrado - "Bombando Cidadania" -, que, no Recife, visa a inserir uma população de baixa renda na sociedade. Segundo comentário da Coordenadora Regional (NE) do Instituto Walmart, ao entender que esse primeiro programa trouxe um efeito bastante positivo para o desenvolvimento de uma parte da população que até então se apresentava excluída da sociedade, foi possível disseminálo para o Pará.

Além dessas interações, percebe-se a necessidade de relação da empresa para com instituições não governamentais (MONT; PLEPYS, 2007). Com isso, buscando entender de forma ampla e completa como se apresentam as possíveis contribuições do Walmart Brasil, a partir da apresentação de algumas das interações sociais que são praticadas, no que se refere à marca Hiper Bompreço, para uma melhor esquematização, entende-se como necessária a visualização de quais e como os stakeholders estudados estão articulados para a efetivação desse novo padrão de 
consumo, de acordo com a rede de influências de Michaelis (2003), como forma de complementar as análises até então realizadas.

\subsubsection{Visualização da contribuição para o consumo sustentável}

A partir das considerações apresentadas até então, torna-se possível, por meio do quadro-resumo (Quadro 2), compreender amplamente como ocorre o processo contributivo do Walmart Brasil para o consumo sustentável. Assim, podemse realizar as inferências necessárias para as conclusões de pesquisa. Para tanto, percebe-se que deve haver, para cada critério, a indicação da situação contributiva das ações na visão do pesquisador. Assim, assumem-se três níveis de análise: Favorável, para aquele critério que claramente possui uma contribuição para o CS; Em desenvolvimento, para o critério que possui iniciativas por parte da empresa; e Desfavorável, para aqueles que não são identificados nas ações da empresa.

Quadro 2 - Quadro-resumo da contribuição da empresa para o Consumo Sustentável

\begin{tabular}{|c|c|c|c|}
\hline Dimensão & Categoria Teórica & Critérios & Situação contributiva \\
\hline \multirow{8}{*}{$\begin{array}{c}\text { Desenvolvimento de } \\
\text { novas tecnologias e } \\
\text { práticas }\end{array}$} & \multirow{4}{*}{ Ecoeficiência } & Reciclagem & Desfavorável \\
\hline & & Reutilização & Desfavorável \\
\hline & & Estrutura física da loja & Desfavorável \\
\hline & & Certificação & Desfavorável \\
\hline & \multirow{4}{*}{$\begin{array}{l}\text { Práticas de consumo } \\
\text { próprias }\end{array}$} & Água & Em desenvolvimento \\
\hline & & Energia & Em desenvolvimento \\
\hline & & Gestão de resíduos & Em desenvolvimento \\
\hline & & Transportes & Desfavorável \\
\hline \multirow{6}{*}{$\begin{array}{c}\text { Mudanças nos } \\
\text { incentivos econômicos }\end{array}$} & \multirow[t]{2}{*}{ Incentivos do governo } & $\begin{array}{l}\text { Comportamento } \\
\text { reativo }\end{array}$ & Em desenvolvimento \\
\hline & & Negociação & Em desenvolvimento \\
\hline & \multirow[t]{2}{*}{$\begin{array}{l}\text { Elos na cadeia de } \\
\text { suprimentos }\end{array}$} & $\begin{array}{l}\text { Disseminação de } \\
\text { práticas responsáveis }\end{array}$ & Favorável \\
\hline & & $\begin{array}{l}\text { Capacidade de } \\
\text { influência }\end{array}$ & Favorável \\
\hline & \multirow[b]{2}{*}{ Edição de escolha } & $\begin{array}{l}\text { Processo decisório } \\
\text { responsável }\end{array}$ & Em desenvolvimento \\
\hline & & $\begin{array}{l}\text { Análise da procedência } \\
\text { do produto a ser } \\
\text { vendido }\end{array}$ & Em desenvolvimento \\
\hline \multirow{2}{*}{$\begin{array}{l}\text { Mudança cultural na } \\
\text { rede de influências }\end{array}$} & \multirow[b]{2}{*}{ Cidadania corporativa } & $\begin{array}{l}\text { Boa cidadania } \\
\text { corporativa }\end{array}$ & Favorável \\
\hline & & $\begin{array}{l}\text { Disseminação do } \\
\text { consumo consciente } \\
\text { junto aos funcionários }\end{array}$ & Favorável \\
\hline
\end{tabular}




\begin{tabular}{|l|l|l|c|}
\hline \multirow{2}{*}{ Marketing responsável } & $\begin{array}{l}\text { Composto de marketing } \\
\text { responsável }\end{array}$ & Em desenvolvimento \\
\cline { 2 - 3 } & Relatório social & Favorável \\
\cline { 2 - 3 } & $\begin{array}{l}\text { Relação com a mídia } \\
\text { Diálogo com } \\
\text { stakeholders }\end{array}$ & $\begin{array}{l}\text { Relação com a } \\
\text { comunidade }\end{array}$ & Favorável \\
\cline { 2 - 4 } & $\begin{array}{l}\text { Relação com } \\
\text { instituições não } \\
\text { governamentais }\end{array}$ & Favorável \\
\hline
\end{tabular}

Fonte: Elaborado pelo autor, 2013.

De acordo com a visão de todos os critérios que foram analisados, percebe-se que foi apresentada, em oito das categorias, uma visão favorável para contribuição efetiva da empresa no contexto do consumo sustentável. No entanto, deve-se considerar que existe, além das variáveis em desenvolvimento, uma grande quantidade de critérios desfavoráveis à atuação positiva do Hiper Bompreço em Recife, o que deve ser observado pela empresa para que, caso seja interesse da mesma, haja uma reestruturação da maneira como ela deve se comportar no mercado. Esse fato pode ser observado, principalmente, no que se refere à dimensão do desenvolvimento de novas tecnologias e práticas.

Diante de todas as considerações realizadas, entende-se que há na empresa, mesmo com as muitas desconfianças sociais sobre a conduta no mercado, um direcionamento, ainda que indireto, para a facilitação, por meio de suas práticas empresariais responsáveis de ações, em favor da construção de um padrão sustentável de consumo no varejo de supermercados. Esse fato indica que o Walmart Brasil, com o foco no Hiper Bompreço, encontra-se envolvido com sua rede de influências de maneira tal que as contribuições positivas que o mesmo venha a assumir no mercado perpassam por um processo de interação social, que pode ser visualizado a partir da rede apresentada na figura a seguir. 
Figura 1 - Mapa da rede de influências do Hiper Bompreço para o consumo sustentável

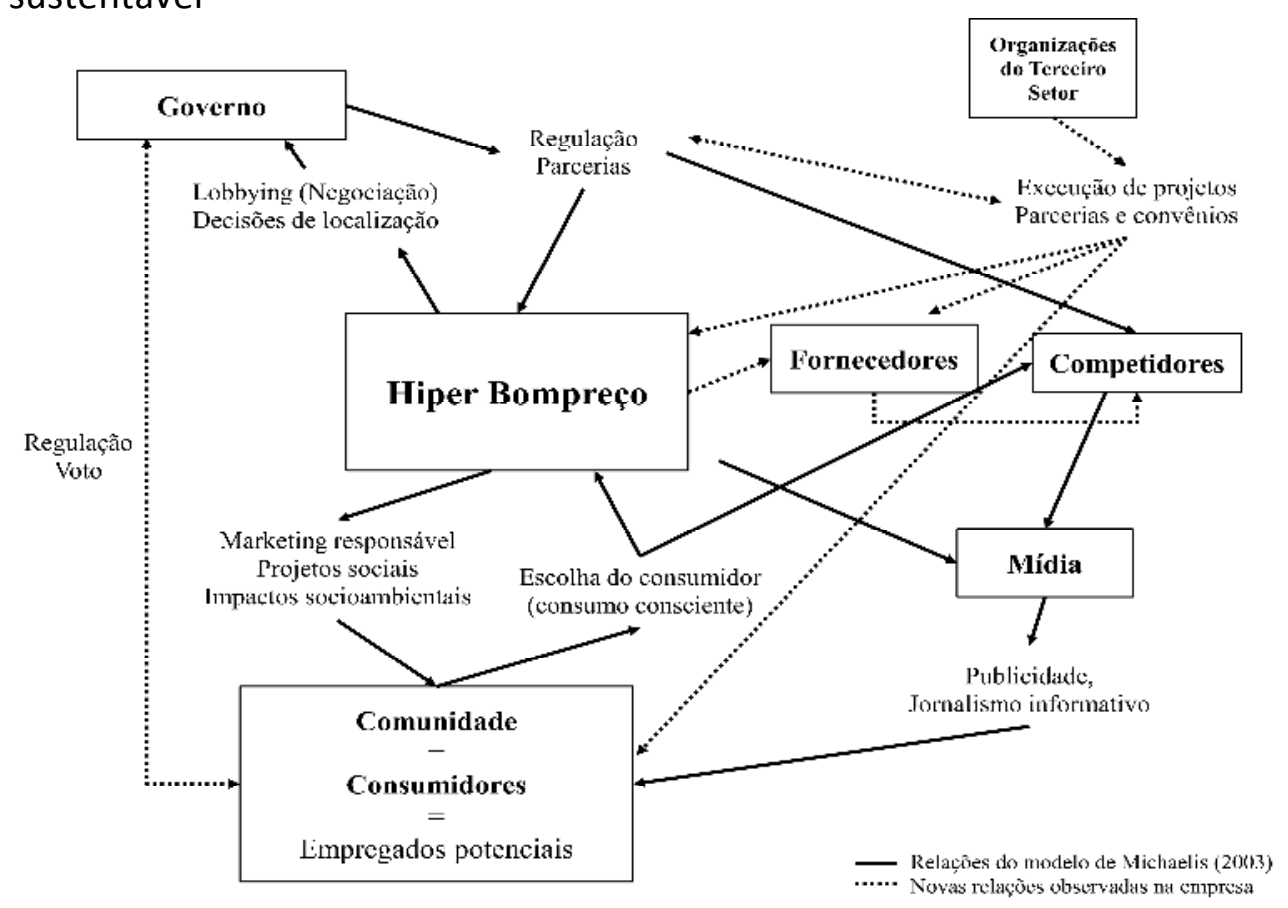

Fonte: Pesquisa de campo (2011) a partir de Michaelis (2003).

Como se pode observar na Figura 1, a empresa desenvolve um conjunto de parcerias que envolve algumas das interações sociais que são apresentadas por Michaelis (2003) em seu mapeamento. No entanto, nem todas as que foram apresentadas foram verificadas, além de novas interações surgiram, o que ratifica o questionamento realizado durante a discussão teórica sobre ao mapeamento realizado pelo autor em seu trabalho. Dessa maneira, percebe-se que não existem interações com instituições financeiras e universidades, e que surge a interação com organizações do Terceiro Setor que não estão contempladas na indicação do autor. Além disso, novas relações foram observadas nessa rede de influências, o que embasa a indicação de contribuição efetiva da empresa para o consumo sustentável.

Assim sendo, a partir do reconhecimento evolutivo das ações do Walmart Brasil para práticas responsáveis, na medida em que as mesmas foram incorporadas como um dos pilares estratégicos, e das relações e parcerias que são e estão sendo desenvolvidas pela empresa, tornou-se possível mostrar as contribuições da empresa estudada, bem como as possíveis formas de atuação que podem ser desenvolvidas por 
outras empresas de supermercados para o Consumo Sustentável, o qual, sob a ótica do desenvolvimento sustentável, pode ser almejado e estimulado nas relações de produção e consumo identificadas no setor.

\section{CONSIDERAÇÕES FINAIS}

Impulsionadas pelas práticas voltadas para questões socioambientais, cada vez mais as empresas estão buscando adequar suas atividades à nova atuação mercadológica. Nesse contexto, direcionados para o alcance do desenvolvimento sustentável, diferentes atores devem estar em parceria com esse ator, contribuindo com um novo comportamento. No estudo do consumo sustentável, as interações que são necessárias facilitam uma reestruturação nas relações de produção e consumo de modo tal a criar, em determinado setor econômico, novas formas de atuação empresarial. Esses aspectos foram apresentados ao longo da discussão teórica do estudo e embasaram a identificação empírica dos aspectos levantados.

Com essa visão, identificou-se, ao realizar as análises, que nem todas as variáveis puderam ser identificadas em sua plenitude na empresa estudada em meio às interações sociais, mas, tendo em vista que a articulação realizada almeja trabalhar com um conjunto de categorias aplicável a qualquer empresa integrante do setor, entende-se como positiva a sua realização. Em meio a essas interações identificou-se que deve haver interação com diferentes stakeholders, todavia, ao seguir o mapeamento desenvolvido por Michaelis (2003), identificou-se a necessidade de se acrescentar um novo ator, que até então não era considerado. Desse modo, entendese que a rede de influências para o consumo sustentável deve ser visualizada com na Figura 2, a seguir. 
Figura 2 - Novo mapa da rede de influências para o consumo sustentável

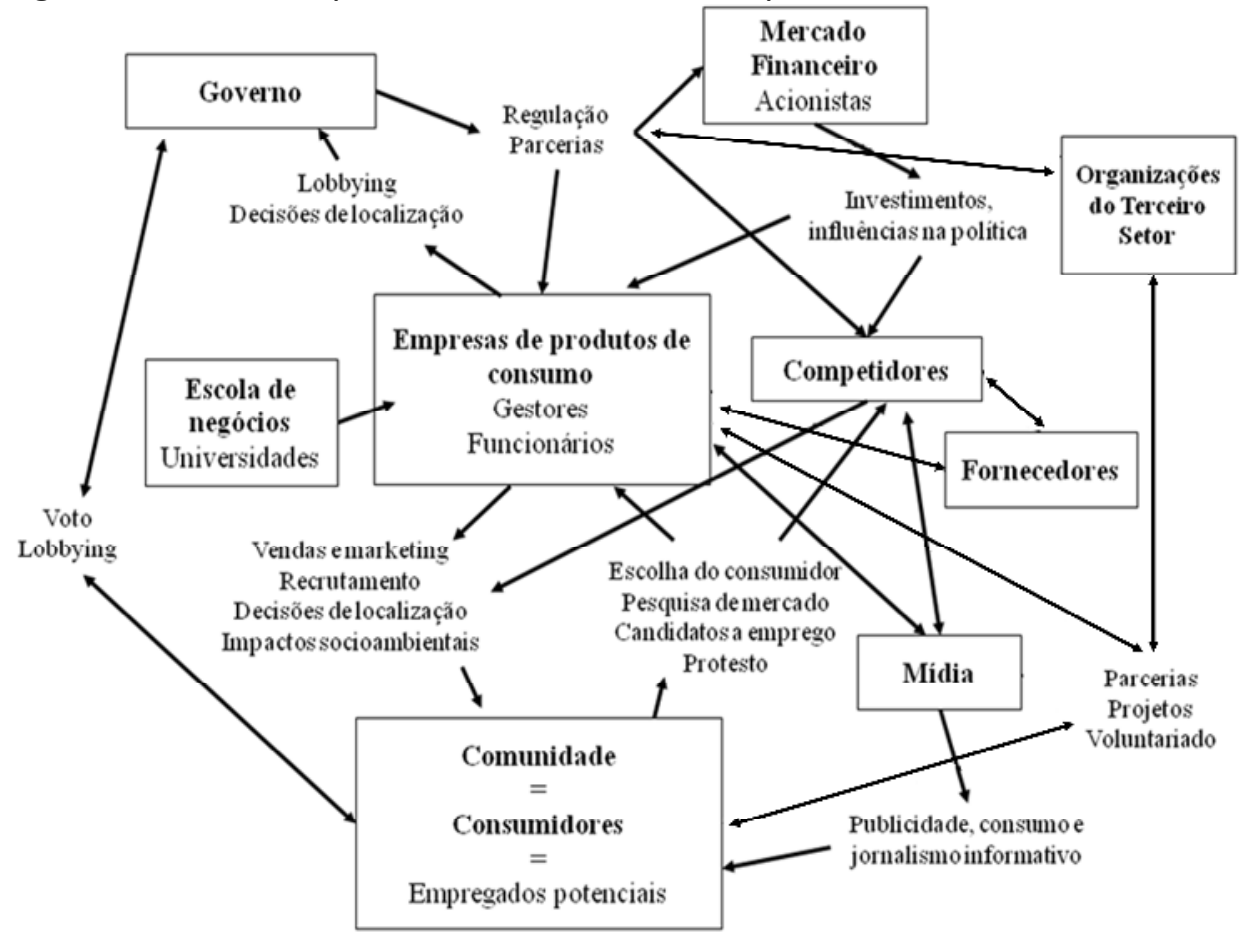

Fonte: Elaborado pelo autor a partir dos Dados de pesquisa (2011).

A partir da ilustração anterior, percebe-se que novas interações foram identificadas, de maneira tal que com a inserção do ator social que ainda não estava contemplado (organizações do Terceiro Setor), a complexidade para o alcance do Consumo Sustentável foi ampliada, já que mais interações são necessárias nesse sentido. A inclusão desse ator se faz necessária tendo em vista que o mesmo é capaz de realizar o intermédio entre as ações públicas, que por algum motivo não estão sendo realizadas, bem como para auxiliar as empresas na realização de suas atividades, por meio de parcerias e convênios. Desse modo, a partir dos estudos desenvolvidos no âmbito reflexivo, as instituições podem capturar as informações que Ihes forem pertinentes e melhor atuar em seu setor econômico.

Define-se como limitações da pesquisa o estudo de apenas uma marca, bem como a realização de poucas entrevistas na empresa. A partir dessas considerações, fica clara a contribuição teórico-empírica, já que o objetivo de apresentar a contribuição do Walmart Brasil e suas interações foi alcançado. Portanto, diante de todas as indicações e evidenciações, assume-se como verdadeira a premissa da pesquisa, pois, com a incorporação de práticas responsáveis, as empresas, em meio 
às interações sociais em que estão inseridas, podem auxiliar para o consumo sustentável, fato esse que foi verificado e identificado neste estudo.

\title{
THE CONTRIBUTION OF THE RETAIL TO SUSTAINABLE CONSUMPTION:
}

\section{AN ANALYSIS OF WAL-MART BRAZIL PRACTICES AMONG ITS STAKEHOLDERS}

\begin{abstract}
Immersed in a set of interactions between different stakeholders in the market, the business can contribute to a new pattern of sustainable consumption. With this, the purpose of this study is to identify the contribution of Wal-Mart Brazil to sustainable consumption in retail supermarkets in Recife/PE under the perspective of social interactions presented by Michaelis (2003). With focus exploratory and qualitative approach to research conducted in the form of a case study considers sustainable consumption as a background of search, to recognition of relations between the actors selected, thus we identify a positive contribution of the company in eight criteria reviewed with most other developing for a change in the sector. Among the findings, we feature the need to add the third sector organizations to network influences, considering the influence and importance this actor to social interactions. With this, the greatest contribution of paper is at show the possibility of implementation of sustainable consumption.
\end{abstract}

Keywords: Sustainable Consumption. Stakeholders. Retail. Supermarkets.

\section{REFERÊNCIAS}

ASSADOURIAN, E. Ascensão e queda das culturas de consumo. In: WORLDWATCH INSTITUTE. Estado do Mundo, 2010: estado do consumo e o consumo sustentável. Salvador: Uma, 2010.

BARDIN, L. Análise de Conteúdo. 4. ed. Lisboa: Edições 70, 2009.

BUARQUE, S. C. Construindo o desenvolvimento local sustentável. 4. ed. Rio de Janeiro: Garamond, 2008.

R. eletr. estrat. neg., Florianópolis, v.6, n.2, p.66-93, mai./ago. 2013 
A CONTRIBUIÇÃO DO VAREJO PARA O CONSUMO SUSTENTÁVEL: UMA ANÁLISE DAS PRÁTICAS DO WALMART BRASIL JUNTO AOS SEUS STAKEHOLDERS

Minelle Enéas da Silva

BUENSTFORT, G.; CORDES, C. Can sustainable consumption be learned? A model of cultural evolution. Ecological Economics, v. 67, n. 4, p.646-657. November/2008.

CANEPA, C. Cidades sustentáveis: o município como lócus da sustentabilidade. São Paulo: RCS, 2007.

CARROLL, A. B. The four faces to corporate citizenship. Business and Society Review, v. 1, n. 100-101, p. 1-7, 1998.

CNUMAD - CONFERÊNCIA DAS NAÇÕES UNIDAS SOBRE MEIO AMBIENTE E DESENVOLVIMENTO. Agenda 21 Global. 1992. Disponível em:

<http://www.mma.gov.br/sitio/index.php?ido=conteudo.monta\&idEstrutura=18\&idCo nteudo=575\&idMenu=9065>. Acesso em: 10 set. 2010.

COOPER, D. R.; SCHINDLER, P. Métodos de pesquisa em administração. 7. ed. Porto Alegre: Bookman, 2003.

CORTEZ, A. T. C.; ORTIGOZA, S. A. G. Consumo Sustentável: conflitos entre necessidades e desperdício. São Paulo: UNESP, 2007.

CRESWELL, J. W. Projeto de pesquisa: métodos qualitativo, quantitativo e misto. 3. ed. Porto Alegre: Artmed/Bookman, 2010.

ELKINGTON, J. Canibais com garfo e faca. São Paulo: Makroon Books, 2001.

FLICK, U. Uma introdução à pesquisa qualitativa. Porto Alegre: Bookman, 2004.

FOLADORI, G. Por uma sustentabilidad alternativa. Uruguai: Colección Cabichui, 2005.

GOLDENBERG, M. A arte de pesquisar: como fazer pesquisa qualitativa em ciências sociais. Rio de Janeiro: Record, 2009.

GUNTHER, M. The Green Machine. Fortune Magazine, United States. July/2006.

Disponível em:

<http://money.cnn.com/magazines/fortune/fortune_archive/2006/08/07/8382593/>. Acesso: Dez. 2011.

JACKSON, T.; MICHAELIS, L. Policies for sustainable consumption. A Report to the sustainable development commission. $1^{\text {st }}$ Edition. University of Surrey. September, 2003. Anais eletrônicos... Disponível em:

<http://portal.surrey.ac.uk/pls/portal/docs/PAGE/ENG/RESEARCH/CES/CESRESEARCH/ ECOLOGICAL-ECONOMICS/PROJECTS/FBN/POLICIES.PDF> Acesso: Jul. 2010. 
JACKSON, T. Negotiating Sustainable Consumption: A review of the consumption debate and its policy implications. Energy \& Environment, v. 15, n. 6, p.1027-1051. Essex. November/2004.

Sustainable Consumption. In: ATKINSON, Giles; DIETZ, Simon; NEUMAYER, Eric (editors). Handbook of Sustainable Development. Edward Elgar Publishing: London/UK, 2007.

KTE'PI, B. Sustainable Development. In: Encyclopedia of Business In Today's World. Sage Publications Online. 2009.

MÁLOVICS, G.; CSIGÉNÉ, N. N.; KRAUS, S. The role of corporate social responsibility in strong sustainability. The Journal of Socio-Economics, v. 37, n. 3, p. 907-918. June/2008.

MARCONI, M. A.; LAKATOS, E. M. Técnicas de pesquisa: Planejamento e execução de pesquisas, amostragens e técnicas de pesquisa, elaboração, análise e interpretação de dados. 7. ed. São Paulo: Atlas, 2010.

MARTINS, M. F.; CÂNDIDO, G. A. Índice de Desenvolvimento Sustentável para Municípios (IDSM): metodologia para cálculo e análise do IDSM e a classificação dos níveis de sustentabilidade para espaços geográficos. João Pessoa: SEBRAE-PB, 2008.

MICHAELIS, L. Sustainable consumption and production. In: DODDS, F.; MIDDLETON, T. Earth Summit 2002: A new deal. 2a Edition. Earth scan Online. 2000.

The role of business in sustainable consumption. Journal of Cleaner Production, v.11, n. 8, p. 915-921. 2003.

MONT, O.; PLEPYS, A. Sustainable consumption progress: should we be proud or alarmed? Journal Cleaner Production, v.16, n. 4, p. 531-537. March/2007.

MUSTER, V. Companies promoting sustainable consumption of employees. Journal of consumer policy. V. 34, n. 1, p.161-174. March/2011.

OLIVEIRA, M. M. Como fazer pesquisa qualitativa. Recife: Bagaço, 2005.

PEATTIE, K. Toward sustainable organizations for the 21st century. 21st Century Management: A Reference Handbook. Sage Publications Online. 2007.

PNUMA - PROGRAMA DAS NAÇÕES UNIDAS PARA O MEIO AMBIENTE. Rumo ao consumo sustentável na América latina e caribe. In: 1 Workshop SOBRE CONSUMO SUSTENTÁVEL NA AMÉRICA LATINA E CARIBE, . 2001, São Paulo. Anais eletrônicos... São Paulo: PNUMA, 2011. Disponível em:

<http://www.pnuma.org/industria/documentos/conslacp.pdf>. Acesso em: jul. 2010. 
A CONTRIBUIÇÃO DO VAREJO PARA O CONSUMO SUSTENTÁVEL: UMA ANÁLISE DAS PRÁTICAS DO WALMART BRASIL JUNTO AOS SEUS STAKEHOLDERS

Minelle Enéas da Silva

PORTILHO, M. F. F. Sustentabilidade Ambiental, consumo e cidadania. São Paulo:

Cortez, 2005.

SACHS, I. Rumo à ecossocioeconomia: Teoria e prática do desenvolvimento. São Paulo: Cortez, 2007.

SCHUMACHER, E. F. Lo pequeño es hermoso. 3. ed. Espana: Tursen S.A, 2001.

SILVA, M. E. A contribuição de práticas empresariais responsáveis para o consumo sustentável no varejo de supermercados: O caso Walmart Brasil. 2011. 137p. Dissertação (Mestrado em Administração) - Programa de Pós-Graduação em Administração da Universidade Federal de Pernambuco, Recife, 2011.

SILVA, M. E.; GÓMEZ, C. R. P. O papel do governo e a prática do consumo sustentável: Como esse stakeholder atua no setor elétrico? Revista Eletrônica de Ciência Administrativa, Campo Largo - PR, v. 10, n. 2, p. 107-123. Jul.-Dez./2011.

SILVA, M. E.; SANTOS, C. F. O. S. A estratégia socioambiental do Walmart Brasil: Entendendo suas ações e as interações em sua rede de stakeholders. In: ENCONTRO DA Associação Nacional de Pós-Graduação em Administração, 35., 2011, . Anais... Rio de Janeiro: ANPAD, 2011.

STEINER, G. A.; STEINER, J. F. Business, government and society: A managerial perspective, text and cases. 11. ed. Nova York: McGraw-Hill/Irwin, 2006.

TUKKER, A. et al. Fostering change of sustainable consumptiom and production: an evidence based view. Journal of cleaner production, v. 16, n. 11, p. 1218-1225. 2008.

VAN BELLEN, H. M. Indicadores de Sustentabilidade: Uma análise comparativa. Rio de Janeiro: FGV, 2005.

WALMART BRASIL. Institucional Walmart. 2010a. Disponível em: <http://www.walmartbrasil.com.br/institucional/nomundo.aspx>. Acesso em: set. 2010.

Relatório de sustentabilidade 2009 (Exercício 2008). 2009. Disponível em: <http://www.walmartsustentabilidade.com.br/_pdf/relatorios/walmart-relatorio-desustentabilidade-2009.pdf> Acesso em: dez. 2010.

Relatório de sustentabilidade 2011 (Exercício 2010). 2011. Disponível em: $<$ http://www.walmartsustentabilidade.com.br/relatorioonline/downloads/Walmart_RA10_pt. pdf> Acesso em: jul. 2011.

WBCSD - World Business Council for Sustainable Development. Sustainable consumption:

R. eletr. estrat. neg., Florianópolis, v.6, n.2, p.66-93, mai./ago. 2013 
A CONTRIBUIÇÃO DO VAREJO PARA O CONSUMO SUSTENTÁVEL: UMA ANÁLISE DAS PRÁTICAS DO WALMART BRASIL JUNTO AOS SEUS STAKEHOLDERS

Minelle Enéas da Silva

facts e trends - from a business perspective. 2008. Disponível em:

$<$ http://www.wbcsd.org/

DocRoot/I9Xwhv7X5V8cDIHbHC3G/WBCSD_Sustainable_Consumption_web.pdf>. Acesso em: maio 2011.

WCED - WORLD COMISSION ON ENVIRONMENT AND DEVELOPMENT. Report Our common future. Genebra, 1987. Disponível em: <http://www.un-

documents.net/wced-ocf.htm.>. Acesso em: set. 2010. 